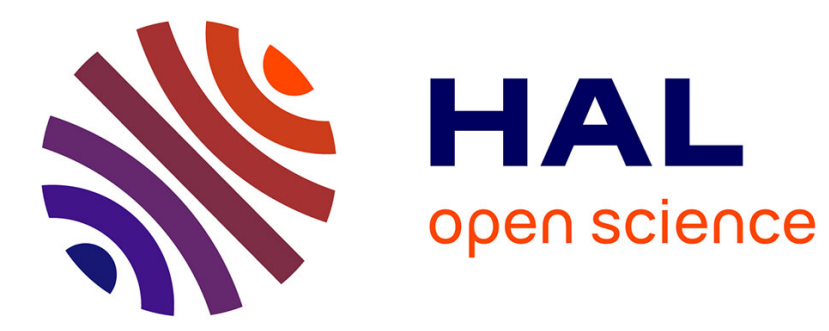

\title{
Large shocks in the volatility of the Dow Jones Industrial Average index: 1928-2013
}

Amélie Charles, Olivier Darné

\section{To cite this version:}

Amélie Charles, Olivier Darné. Large shocks in the volatility of the Dow Jones Industrial Average index: 1928-2013. Journal of Banking and Finance, 2014, 43, pp.188-199. 10.1016/j.jbankfin.2014.03.022 . hal-01122507

HAL Id: hal-01122507

https://hal-audencia.archives-ouvertes.fr/hal-01122507

Submitted on 29 Apr 2015

HAL is a multi-disciplinary open access archive for the deposit and dissemination of scientific research documents, whether they are published or not. The documents may come from teaching and research institutions in France or abroad, or from public or private research centers.
L'archive ouverte pluridisciplinaire HAL, est destinée au dépôt et à la diffusion de documents scientifiques de niveau recherche, publiés ou non, émanant des établissements d'enseignement et de recherche français ou étrangers, des laboratoires publics ou privés. 


\title{
Large shocks in the volatility of the Dow Jones Industrial Average index: 1928-2013
}

\author{
Amélie CHARLES* \\ Audencia Nantes, School of Management
}

Olivier DARNÉ ${ }^{\dagger+}$

LEMNA, University of Nantes

\begin{abstract}
We determine the events that cause large shocks in volatility of the DJIA index over the period 1928-2013, using a new semi-parametric test based on conditional heteroscedasticity models. We find that these large shocks can be associated with particular events (financial crashes, elections, wars, monetary policies, ...). We show that some shocks are not identified as extraordinary movements by the investors due to their occurring during high volatility episodes, especially the 1929-1934, 1937-1938 and 2007-2011 periods.
\end{abstract}

Keywords: Large shocks, Volatility, Stock market.

JEL Classification: C12; G01; N22; N42.

${ }^{*}$ Audencia Nantes, School of Management, 8 route de la Jonelière, 44312 Nantes, France. Email: acharles@audencia.com.

${ }^{\dagger}$ Corresponding author: LEMNA, University of Nantes, IEMN-IAE, Chemin de la Censive du Tertre, BP 52231, 44322 Nantes, France. Tel: +33(0)2 401417 05. Email: olivier.darne@univ-nantes.fr.

${ }^{\ddagger}$ Olivier Darné gratefully acknowledge financial support from the Chaire Finance of the University of Nantes Research Foundation. 


\section{Introduction}

Black Monday, as October 19, 1987, became known, was not just another day; it was the single worst day (in percentage terms) in the Dow's history and therefore unique. (Estrada, 2009).

Indeed, the Dow Jones Industrial Average (DJIA) index sustained a 22.6\% loss on Black Monday. However, large daily swings that are neither unique, unusual nor as dramatic have a substantial impact on stock market returns. Events such as wars, terrorism, and bankruptcy are known as "black swans". ${ }^{1}$ According to Taleb (2007), a black swan is an event with three attributes: (i) It is an outlier, lying outside the realm of regular expectations because nothing in the past can convincingly point to its occurrence; (ii) it carries an extreme impact; and (iii) despite being an outlier, plausible explanations for its occurrence can be found after the fact, thus implying that it is explainable and predictable.

Failing to take explicit account of the fact that such extraordinary movements have occurred in the past - and will occur in the future - is therefore a serious omission (Friedman and Laibson, 1989). Several studies analyze the financial market reactions to major events, by focusing on one type of event. For example, Schwert (1989b, 1990) examine the effect of the 1987 stock market crash, Frey and Kucher (2000) and Choudhry (2010) study the impact of events during World War II, Amihud and Wohl (2004), Rigobon and Sack (2005) and Wolfers and Zitzewitz (2009) explore the impact of the Iraq War, Berkman, Jacobsen and Lee (2011) study the impact of rare disasters, Schwert (1981), Flannery and Protopapadakis (2002), Bomfim (2003), Birz and Lott (2011) and Rangel (2011) investigate macroeconomic announcements, Akhigbe, Martin and Whyte (2005) analyze the effect of the Worldcom bankruptcy, Chen and Siems (2004) and Chesney, Reshetar and Karaman (2011) study the impact of terrorism, Nierderhoffer, Gibbs and Bullock (1970), Reilly and Luksetich (1980), Foerster and Schmitz (1997), Santa-Clara and Valkanov (2003), Bialkowski,

\footnotetext{
${ }^{1}$ See Taylor and Williams (2009) and Olson et al. (2012) for a discussion of "black swans" in the money market.
} 
Gottschalk and Wisniewski (2008) and Jones and Banning (2009) look at the effect of presidential elections, and Nierderhoffer (1971) explores the impact of Presidential illnesses. Most of these studies analyze the effects of events on financial markets where the dates are known, most often using event study methodology.

Other studies purport to identify major shocks due to "unknown" events that affect the stock markets before examining their implications. For example, Bloom (2009) uses the VXO index of implied volatility (1986-2008) as a proxy for uncertainty to show that uncertainty dramatically increases after major economic and political shocks. $\mathrm{He}$ defines majors shocks as those with volatility more than 1.65 standard deviations above the Hodrick-Prescott detrended mean of volatility. Wang et al. (2009) investigate the causes and effects of the eight largest stock market crashes (1962-2007). They define them as a minimum one-day decrease of $5 \%$ in the daily value-weighted market index returns of stocks included in the Center for Research in Security Prices (CRSP) database. Barro and Ursúa (2009) define stock-market crashes as cumulative multiyear returns of $-25 \%$ or less when studying the relation between stock-market crashes and depressions on long-term data (1869-2006) from Global Financial Data. They include the variables in a rare-disaster model to explain the equity premium (Barro, 2006). Cutler et al. (1989) analyze the fifty largest stock movements in the S\&P Composite Stock Index (1947-1987) which are defined as the largest one-day returns (daily changes).

Another way to identify black swans or (infrequent) large shocks is intervention analysis, introduced by Box and Tiao (1975) to attempt to statistically appraise these types of shocks. Intervention analysis is used to assess the impact of a known or unknown event on the time series. The main focus is to estimate the dynamic effect of such events on the series. ${ }^{2}$ No attempt is made here to formally define a black swan. Intervention analysis forms the basis for many outlier modelling procedures. A number of procedures have been developed to identify these outliers on linear models (e.g.,

\footnotetext{
${ }^{2}$ Balke and Fomby (1994), Charles and Darné (2006), and Darné and Charles (2011) use intervention analysis in a linear framework to identify large infrequent shocks in macroeconomic and financial times series.
} 
Tsay, 1986; Chang, Tiao and Chen, 1988; Chen and Liu, 1993). Nevertheless, it is well known that the world is not linear, and neither are financial data. Such extreme movements (in returns) are potentially important in finance and financial economics, especially in modelling volatility of returns, which are an important key to risk management, derivative pricing and hedging, market making, market timing, portfolio selection, monetary policy making, and many other financial activities. Several authors consider outliers in nonlinear setting, especially from autoregressive conditionally heteroscedastic (ARCH) models introduced by Engle (1982) and extended to generalized ARCH (GARCH) by Bollerslev (1986) (see, e.g., Sakata and White, 1998; Franses and Ghijsels, 1999; Franses and van Dijk, 2000; Charles and Darné, 2005; Doornik and Ooms, 2005; Zhang and King, 2005; Hotta and Tsay, 2012). The GARCH models, a well-known time-varying variance specification, have been developed to capture the two most important stylized facts of returns of financial assets, which are heavy-tailed distribution and volatility clustering.

In this paper, the detection and identification of large shocks in volatility of the DJIA index spanning October 2, 1928 to August 30, 2013 results from the semiparametric procedure to detect additive outliers proposed by Laurent, Lecourt and Palm (LLP) (2013) based on the GJR model of Glosten, Jagannathan, and Runkle (1993) that accounts for the so-called leverage effect. ${ }^{3}$ We determine when these (positive and negative) large changes in volatility of daily returns occur during the period. We use a moving subsample (10 years) window to take into account the different volatility levels of the DJIA in the detection of the large shocks, namely periods with high volatility and periods with low volatility. This approach allows thus to identify large shocks as extraordinary movements perceived by the investors. The larger changes in percentage have different consequences and perceptions when the market is within a high volatility period compared with a low volatility period or a stable period,

\footnotetext{
${ }^{3}$ Stock returns exhibit some degree of asymmetry in their conditional variances, i.e. that market participants overreact to bad news as compared to good news (Black, 1976; Christie, 1982; French, Schwert and Stambaugh, 1987; Bollerslev, Chow, and Kroner, 1992).
} 
especially in a context of uncertainty about the future profitability of equities and their risk. We try to associate the date of each outlier with a specific (economic, political or financial) event that occurred near that date, and many of them seem to be associated with the same event patterns. We find that large shocks in volatility of the DJIA are principally due to major financial crashes (1929, 1987, and 1997-98), US elections, wars (e.g., Spanish Civil War, World War II, Korean war, and Gulf war), monetary policy during recessions, macroeconomic news and declarations about the economic situation, terrorist attacks, bankruptcy, and regulation. We also find that some negative and positive high returns experienced by the DJIA are not identified as outliers, namely as extraordinary (rare) movements, due to the very high volatility of some periods (see, e.g., Officer, 1973; Schwert, 1989a). This can be explained by differing consequences and perceptions of the investors on larger changes in percentage when the market is within a high volatility period compared with a low volatility period or a stable period. For example, a percentage change of $-4 \%$ in returns will be not perceived in the same way by the investors when the market is within a high or a low volatility period. This percentage change considered as a significant shock under a low volatility regime may become insignificant under a high volatility regime. Therefore, we use the iterative cumulative sums of squares (ICSS) algorithm proposed by Inclán and Tiao (1994) and improved by Sansó et al. (2004) to identify sudden shifts in volatility of the DJIA. We find different regime changes in volatility (high, medium and low volatility), especially episodes of high volatility occurring in 1929-1934, 1937-1938 and 2007-2011. Further, in contrast to Schwert (2011), we show that the period of the 2007-08 financial crisis and the related recession (2007-2011) exhibit the same characteristic than the 1929-1934 recession period: very high levels of volatility on prolonged periods (many years).

The paper is structured as follows: Section 2 describes the methodology identifying outliers based on a conditional heteroscedasticity model. The empirical framework is discussed in Section 3, along with the events associated with infrequent 
large shocks in DJIA volatility. Section 4 presents volatility changes in the DJIA. A discussion on outliers and risk management is given in Section 5. The conclusion is drawn in Section 6.

\section{Outlier detection in GJR model}

Several studies have showed that financial data may be affected by contaminated observations (Balke and Fomby, 1994; Charles and Darné, 2005). This type of observations, called outliers, reflects extraordinary, infrequently occurring events or shocks that have important effects on macroeconomic and financial time series. There are several methods for detecting outliers in nonlinear setting, such as the method for additive jumps detection proposed by Franses and Ghijsels (1999) and Franses and van Dijk (2000). Here we use the semi-parametric procedure to detect additive outliers proposed by Laurent, Lecourt and Palm (LLP) (2013). ${ }^{4}$ Their test is similar to the non-parametric tests for jumps proposed by Lee and Mykland (2008) and Andersen, Bollerslev, and Dobrev (2007) for daily data. This method allows us to examine the large shocks that affected the DJIA returns.

Consider the returns series $r_{t}$, which is defined by $r_{t}=\log P_{t}-\log P_{t-1}$, where $P_{t}$ is the observed price at time $t$, and consider the $\operatorname{ARMA}(p, q)-\operatorname{GARCH}(1,1)$ model

$$
\begin{aligned}
& \phi(L)\left(r_{t}-\mu\right)=\theta(L) \varepsilon_{t} \quad \text { or } \quad r_{t}=\mu_{t}+\varepsilon_{t}, \\
& \varepsilon_{t}=z_{t} \sqrt{\sigma_{t}^{2}}, \\
& \varepsilon_{t} \sim N\left(0, \sqrt{\sigma_{t}^{2}}\right), \quad z_{t} \sim \text { i.i.d.N }(0,1), \\
& \sigma_{t}^{2}=\omega+\alpha_{1} \varepsilon_{t-1}^{2}+\beta_{1} \sigma_{t-1}^{2}
\end{aligned}
$$

where $L$ is the lag operator, $\phi(L)=1-\sum_{i=1}^{p} \phi_{i} L^{i}$ and $\theta(L)=1-\sum_{i=1}^{q} \theta_{i} L^{i}$ are

\footnotetext{
${ }^{4}$ Laurent et al. (2013) critic the sequential test for outliers proposed by Franses and Ghijsels (1999) in two ways: (i) the critical values have to be simulated and depend on some unknown parameter values of the GARCH model and therefore the size of the test can not be controlled; and (ii) the test suffers from the so-called outlier masking problem because it is based on a Quasi-Maximum Likelihood estimate of the GARCH model, which is known to be non-robust to additive outliers (Carnero et al., 2007, 2012). They show that their test does not suffer from those drawbacks.
} 
polynomials of orders $p$ and $q$, respectively, such that $\mu_{t}=\mu+\sum_{i=1}^{\infty} \lambda_{i} \varepsilon_{t-i}$ is the conditional mean of $r_{t}$, where $\lambda_{i}$ 's are the coefficients of $\lambda(L)=\phi^{-1}(L) \theta(L)=$ $1+\sum_{i=1}^{\infty} \lambda_{i} L^{i}$, and $\sigma_{t}^{2}$ is the conditional variance of $r_{t}$.

Consider the return series with an independent additive outlier component $a_{t} I_{t}$, with outlier size $a_{t}$

$$
r_{t}^{*}=r_{t}+a_{t} I_{t}
$$

where $r_{t}^{*}$ denotes observed financial returns and $I_{t}$ is generated by some outlier process such as a Poisson process. The model for $r_{t}^{*}$ has the properties that an outlier $a_{t} I_{t}$ will not affect $\sigma_{t+1}^{2}$ (the conditional variance of $r_{t+1}$ ), and it allows for non-Gaussian fat-tailed conditional distributions of $r_{t}^{*}$.

Let us denote $\widetilde{\mu}_{t}$ and $\widetilde{\sigma}_{t}$ estimates of $\mu_{t}$ and $\sigma_{t}^{2}$ in equations (1) and (2) that are robust to the potential presence of the additive outliers $a_{t} I_{t}$ (i.e. estimated on $r_{t}^{*}$ and not on $r_{t}$ ). The robust estimations of $\widetilde{\mu}_{t}$ and $\widetilde{\sigma}_{t}$ are based on the bounded innovation propagation (BIP)-ARMA proposed by Muler, Peña and Yohai (2009) and the BIPGARCH(1,1) proposed by Muler and Yohai (2008), respectively.The BIP-ARMA and BIP-GARCH(1,1) are defined as

$$
\begin{aligned}
& \widetilde{\mu}_{t}=\mu+\sum_{i=1}^{\infty} \lambda_{i} \omega^{M P Y}\left(\widetilde{J}_{t-i}\right) \\
& \widetilde{\sigma}_{t}^{2}=\omega+\alpha_{1} \widetilde{\sigma}_{t-1}^{2} c_{\delta} \omega_{k_{\delta}}^{M P Y}\left(\widetilde{J}_{t-1}\right)^{2}+\beta_{1} \widetilde{\sigma}_{t-1}^{2},
\end{aligned}
$$

where $\omega_{k_{\delta}}^{M P Y}($.$) is the weight function, and c_{\delta}$ a factor ensuring the conditional expectation of the weighted squared unexpected shocks to be the conditional variance of $r_{t}$ in absence of jumps (Boudt et al., 2013). Laurent et al. (2013) extend the BIPGARCH to the BIP-GJR $(1,1)$, i.e. the robust version of the GJR $(1,1)$ model of Glosten, Jagannathan, and Runkle (1993) that accounts for the so-called leverage effect, i.e.

$$
\widetilde{\sigma}_{t}^{2}=\omega+\alpha_{1} \widetilde{\sigma}_{t-1}^{2} c_{\delta} \omega_{k_{\delta}}^{M P Y}\left(\widetilde{J}_{t-1}\right)^{2}+\gamma_{1} D_{t-1} \widetilde{\sigma}_{t-1}^{2} c_{\delta} \omega_{k_{\delta}}^{M P Y}\left(\widetilde{J}_{t-1}\right)^{2}+\beta_{1} \widetilde{\sigma}_{t-1}^{2},
$$

where $D_{t-1}=1$ if $\widetilde{J}_{t-1}<0$, and 0 otherwise.

Consider the standardized return on day $t$

$$
\widetilde{J_{t}}=\frac{r_{t}^{*}-\widetilde{\mu}_{t}}{\widetilde{\sigma}_{t}}
$$


The outliers detection rule is as follow

$$
\widetilde{I}_{t}=I\left(\left|\widetilde{J_{t}}\right|>k\right)
$$

where $I($.$) is the indicator function, with \widetilde{I}_{t}=1$ when an outlier is detected at observation $t$ and 0 otherwise, and $k$ is a suitable critical value. The critical values are defined by

$$
k=g_{T, \lambda}=-\log (-\log (1-\lambda)) b_{T}+c_{T},
$$

with $b_{T}=1 / \sqrt{2 \log T}$, and $c_{T}=(2 \log T)^{1 / 2}-[\log \pi+\log (\log T)] /\left[2(2 \log T)^{1 / 2}\right]$. They show that their test do not suffer from size distortions irrespectively of the parameter values of the GJR model from Monte Carlo simulations. Following Laurent et al. (2013) we set $\lambda=0.5$. Given $\widetilde{I}_{t}$, detected outliers can be filtered out from $r_{t}^{*}$ as follows: $\widetilde{r}_{t}=r_{t}^{*}-\left(r_{t}^{*}-\widetilde{\mu}_{t}\right) \widetilde{I}_{t}$.

\section{Empirical study}

\subsection{Data description}

In this section, we examine the DJIA stock market ${ }^{5}$ index spanning the October 2, 1928 to August 30, 2013, namely 21,409 observations. We consider the daily closing prices as the daily observations. Throughout the study, returns are calculated as $r_{t}=100 \times\left(\log P_{t}-\log P_{t-1}\right)$, with $r_{t}$ the $\log$-return of each day, and $P_{t}$ the index level

\footnotetext{
${ }^{5}$ The DJIA is the most-quoted market indicator in newspapers, on TV and on the Internet, and one of most important indexes of the NYSE. Because of its longevity, it became the first to be quoted by other publications. Besides longevity, two other factors play a role in its widespread popularity: It is understandable to most people, and it reliably indicates the basic market trend. The DJIA is comprised by 30 companies that are all prominent in their industries. The calculation of the DJIA is weighted price rather than market capitalization. The component weightings are therefore affected only by changes in the stock prices, in contrast with other indices (such as Nasdaq 100 and S\&P 500), whose weightings are affected by both changes in price and in the number of shares outstanding. Note that the DJIA can not be considered as a benchmark of US stock market due to the fact that the DJIA incorporates a small number of components and is based on large caps. It is more considered as a large caps index. We thank the referee for this comment.
} 
at day $t$. Figure 1 plots the returns of the DJIA. This approach is justified because the thrust of the study is an investigation of market volatility. Subperiod analysis is also appropriate because stock return data may not exhibit stationary covariance over long periods (see Pagan and Schwert, 1990). Accordingly, in this study we consider a 10-year rolling window (about 2,500 observations). ${ }^{6}$

We apply the identification procedure of additive outliers in a GJR model for the series of returns. ${ }^{7}$ Table 1 gives descriptive statistics for the non-adjusted and outlieradjusted return series. The non-adjusted returns are highly non-normal, i.e. showing evidence of negative excess skewness and excess kurtosis. They are leptokurtic (i.e., fat-tailed distribution). The variance of the index prices is thus principally due to infrequent but extreme deviations. The Lagrange Multiplier test for the presence of the ARCH effect clearly indicates that the prices show strong conditional heteroscedasticity, which is a common feature of financial data. In other words, there are quiet periods with small price changes and turbulent periods with large oscillations. The outlier-adjusted returns also exhibit excess kurtosis and conditional heteroscedasticity, although the excess kurtosis decreases dramatically. However, the excess skewness becomes insignificant, suggesting, as shown by Carnero et al. (2001) and Charles and Darné (2005), that outliers may cause significant skewness.

\subsection{A brief history of large shocks in DJIA volatility}

All detected outliers are given in Tables $1-4$, by timing and t-statistics as well as point and percent changes. A number of outliers is found in the daily DJIA - 47 outliers - during the whole period. The probability of a large shock is $0.22 \%$, with 33 negative $(70 \%)$ and 14 positive (30\%) large shocks, suggesting that returns are more affected by negative large shocks than positive large shocks. We also try to associate the date of each outlier with a specific (economic, political or financial) event that

\footnotetext{
${ }^{6}$ We used different window's lengths and we obtained the same results.

${ }^{7}$ We also applied the Bai-Perron test for detecting structural breaks in returns but we found no break.
} 
occurred near that date, presenting the outlier dates in chronological order. ${ }^{8}$ In the following subsections, since many of the identified outliers seem to be associated with the same event patterns we discuss the events using a classification of these patterns: financial crises, elections, wars, monetary policy during the recessions, macroeconomic news and declarations on the economic situation, terrorist attacks, bankruptcy and investigation, regulation, and politico-economic conflicts.

Further, Table 7 displays the 20 largest percentage changes and losses of the DJIA between October 1928 and June 2009. This table updates and completes the work of Schwert (1998) who present the 25 largest daily decreases. ${ }^{9}$ The worst single day in percentage change is October 19,1987 , at $-22.61 \%$. We also find that some negative and positive high returns experienced by the DJIA are not identified as outliers, namely as extraordinary (rare) movements, due to the very high volatility of some periods (see, e.g., Officer, 1973; Schwert, 1989a). This can be explained by differing consequences and perceptions of the investors on larger changes in percentage when the market is within a high volatility period compared with a low volatility period or a stable period, especially in a context of uncertainty about the future profitability of equities and their risk. A percentage change of $-4 \%$ in returns is not perceived in the same way by the investors when the market is within a high or a low volatility period.

\subsubsection{Financial crises}

1929 Stock Market Crash. The crash of 1929 struck the NYSE between the October 24 and 29, 1929. ${ }^{10}$ This event marks the start of the Great Depression. On the day of the crash on October 24, 1929 (Black Thursday), a record-breaking 13 million

\footnotetext{
${ }^{8}$ The events associated with outliers are gathered from financial newspapers. Most of them are also found by Cutler et al. (1989) when analyzing the largest stock movements in the S\&P Composite Stock Index on the 1947-1987 period.

${ }^{9}$ See also the Dow Jones website for a list of the largest daily (point and percentage) changes in the DJIA: http://www.djaverages.com.

${ }^{10}$ See, e.g., White (1990), Rappoport and White (1993), Galbraith (1997) and Bierman (1998) for a discussion of the 1929 stock market crash. See also Shachmurove (2012) for a historical overview of financial crisis in the US.
} 
shares were traded, indicating panic. In the afternoon, five banks contributed about $\$ 20$ million each to buy stock and restore confidence in the market. However, new accumulation of sale orders slumped on the market during the weekend, triggering a severe fall of the DJIA (-13.47\%) on October 28, 1929 (Black Monday). This fall was broad based and did not spare securities of excellent quality (blue chip stocks). During the meeting, a conference of the bankers was held, yet it soothed the stock market only momentarily; investors believed thought that the banks were powerless to stop the fall. On October 29, 1929 (Black Tuesday), the DJIA collapsed by $-11.73 \%$. This severe fall can be explained by the fact that in the middle of the meeting, panic occurred when the market learned of the failure of the Curb brokerage firm. The major banks and financial giants continued their efforts to stem the fall by buying large quantities of stocks to demonstrate their confidence in the market to the public, but their efforts were futile. In addition, the Morgan Bank and several other establishments announced that they would charge their customers a cover of only 25\%. The wall Street Management Committee held a meeting during which the possibility of closing the Stock Exchange (next Saturday) was examined, but finally decided that the Saturday meeting would take place. The Federal Bank Reserve of New York appeared determined to lower the rate of the rediscount from $6 \%$ to $5 \%$ on Thursday. In the interim, it still reduced the rate of acceptances by $\frac{1}{8} \%$. The general feeling was slightly less pessimistic. The investors believed that the support actions of the banks would be effective.

Wall Street began to recover from this crisis on October 30, $1929(+12.34 \%$ for the DJIA), nearly offsetting the fall of the previous day. This recovery is due to massive purchases carried out by banks, investment trusts and insurance companies. The governors of the Stock Exchange decided to close on Friday and Saturday to allow the personnel to rest.

The President Hoover's announcement that he would sign the Hawley-Smoot Tariff Act on imported goods on June 16, 1930, involved the fall of the DJIA by $-7.87 \%$. On June 22, 1931, the DJIA rose to $11.90 \%$ which can be attributed to President Herbert Hoover's proposal of a one-year moratorium on $\$ 250$ billion of war debt owed to 
the US government by foreign powers. This plan was regarded as the most constructive economic development in two years, and was expected to stabilize international conditions tremendously. A strong rise occurred on October 6, 1931, driven by the noise of the formation of a powerful banking syndicate whose the aim was to repossess some assets immobilized in several large financial institutions $(+14.87 \%$ for the DJIA).

1987 Stock Market Crash. On October 19, 1987, the DJIA sustained a $-22.61 \%$ collapse (the largest one-day drop in the history of major stock market indexes from 1928 through the end of 2010), known as "Black Monday". ${ }^{11}$ This spectacular fall can be explained by the declarations of Treasury Secretary James Baker on the week-end, threatening Germany, which raised its interest rates, that it would decrease the dollar further. In this case, the Louvre Accord on the stabilization of currency values could be called into question. Therefore, the investors feared a new fall of the dollar and that the government did not support the dollar. The situation was worsened by the Iran-American conflict in the Persian Gulf.

On October 21,1987 , the DJIA rose by $+10.15 \%$ due to the additional decline of interest rates and President Ronald Reagan's stated intention to seek, jointly with Congress, the means of reducing the budget deficit. For investors, this implied the shift from an anti-inflationary policy to an anti-recession policy.

1997-1998 Asian and Russian Crises. The Asian crisis started in Thailand with the financial collapse of the Thai baht in July 1997, and spread through the economies of Southeast Asia. Notably, the Hong Kong Stock Exchange fell steadily (the Hang Seng index lost 33.4\% in eight days). Wall Street suffered accordingly, with a loss of 7.18\% for the DJIA on October 27, 1997. This plunge obliged the NYSE to stop quotations temporarily; it was the first time in US history that these mechanisms, adopted after the crash of 1987 , were applied. ${ }^{12}$

\footnotetext{
${ }^{11}$ See Schwert (1989b, 1990) and Carlson (2006) for a discussion of the 1987 stock market crash.

${ }^{12}$ In response to the market crisis of October 1987 the NYSE instituted circuit breakers to reduce
} 
The Russian crisis (also called the "Ruble crisis") was triggered by the Asian financial crisis and entailed a collapse of the Russian currency (ruble) along with a default of the short-term Russian Government Treasury Bills (the GKO). This caused the Long Term Capital Management (LTCM) hedge fund to default on several billion dollars of financial contracts. On August 26, 1998, the Russian Central Bank terminated rubledollar trading on the MICEX (Moscow Interbank Currency Exchange). The strong fall of the DJIA (-6.37\%) on August 31, 1998, can be explained by a combination of the deterioration of the Russian and Asian crises along with the announcement of bad economic news, namely the declines of both firm profits and household consumption in July $(-0.2 \%)$, which confirmed the slowdown of growth in the US.

\subsubsection{Elections}

Presidential elections. The rise of the DJIA $(+4.37 \%)$ on November 7,1940 , can be attributed to the re-election of the President Franklin Roosevelt, who ran against Republican Wendell Willkie. The Democrat majority to the Senate and the House of Representatives was also preserved.

The victory of Democrat Harry Truman over Republican Thomas Dewey on November 3, 1948, caused a decline on Wall Street $(-3.85 \%$ for the DJIA) because investors expected a Republican win. The fear of reestablishment of income taxes by the Democrats can explain the fall of the DJIA (-3.34\%) on November 5, 1948.

President's Health and Assassination. The large movements of the stock market in September 1955, are due to the illness of President Dwight Eisenhower. The volatility and promote investor confidence. When the DJIA loses 350 points, quotations are suspended for half an hour. The suspension is increased to one hour if the loses are of 550 points. These measurements are supposed to give the operators time to reflect and calm themselves during periods of high market volatility. The SEC approved amendments to Rule 80B (Trading Halts Due to Extraordinary Market Volatility) - effective on April 15, 1998 - which revised the halt provisions and the circuit-breaker levels. The trigger levels for a market-wide trading halt were set at 10\%, $20 \%$ and $30 \%$ of the DJIA, calculated at the beginning of each calendar quarter, using the average closing value of the DJIA for the prior month, thereby establishing specific point values for the quarter. 
announcement of his heart attack prompted a plunge in the DJIA (-6.54\%) on September 26, 1955. In the following days, Wall Street responded strongly to major news concerning the President's health: good news on September 27, $1955(+2.28 \%$ for the DJIA) and bad news on October 10, 1955 (-2.92\% for the DJIA). ${ }^{13}$ The assassination of President John F. Kennedy in Dallas triggered the fall of the DJIA $(-2.89 \%)$ on November 22,1963 . The governor of the NYSE closed the market 30 minutes early due to huge selling orders. The arrest of President Kennedy's assassin can explain the increase on Wall Street on November 26, 1963 (+4.69\% for the DJIA), coupled with along the confidence in Vice-President Lyndon Johnson.

\subsubsection{Wars}

Spanish Civil War. The political situation in Europe, especially the civil war in Spain (the Nationalists marched on Barcelona and conquered Catalonia a few days later), and the deceleration of industrial activity can explain the fall of the DJIA $(-5.52 \%)$ on January 23, 1939.

World War II. On July 26, 1934, the fear of war among some of the important European powers due to the Austrian situation implied the collapse of Wall Street ( $-6.62 \%$ for the DJIA). On October 5, 1937, the DJIA plummeted by $-5.33 \%$ due to the interpretations of the speech by President Franklin Roosevelt in Chicago concerning the positions of the US regarding a possible international conflict. Indeed, the Quarantine Speech given by the President Franklin Roosevelt called for an international "quarantine of the aggressor nations" as an alternative to the political climate of American neutrality and isolationism that was prevalent at the time. The speech was a response to aggressive actions by Italy and Japan, and suggests the use of economic pressure, a forceful response, but less direct than outright aggression.

After the invasion of Poland by Germany on September 1, 1939, Australia, France,

\footnotetext{
${ }^{13}$ Nierderhoffer (1971) studies the relation between Presidential illnesses and stock prices. He shows that there is a strong and consistent stock price movement in the case of death or serious illness of a president. Nierderhoffer finds that out of five president's sickness from 1916 to 1964, Dwight Eisenhower's sickness affected securities prices the most.
} 
New Zealand and United Kingdom declared war on Germany on September 3, 1939. Therefore, on September 5, 1939, traders executed a high volume of purchases to benefit from "war boom" prices, propelling a rise in the DJIA $(+9.52 \%) .{ }^{14}$ The fall of the DJIA (-4.06\%) on September 17, 1939, was caused by the invasion of Poland by the Soviet Union (under the pretext of protecting the Ukrainian and Belorussian minorities). The successive falls of the DJIA $(-2.30 \%,-4.93 \%,-6.80 \%,-4.78 \%$, and $-6.78 \%$ ) between May 10 to 21, 1940, are due to World War II in Europe, notably the German offensive against France and invasion of the neutral nations of Belgium, the Netherlands, and Luxembourg, the flight of Queen Wilhelmina of the Netherlands and her government to London, the surrender of the Dutch army, the flight of the Belgian government after Brussels fell to German forces and the fact that German forces reached the English Channel. The declaration of President Franklin Roosevelt concerning the material help accorded to the Allies prompted a rise in the DJIA $(+4.73 \%)$ on June $12,1940$.

Korean War. The falls of the DJIA on June 1950 can be explained by the Korean War. North Korea attacked South Korea on June 25, 1950, signaling the outbreak of the Korean War (-4.64\% for the DJIA), and North Korean tanks entered Seoul on June 27,1950 (-3.71\% for the DJIA), prompting investors to fear a long war.

Gulf War. The rise of the DJIA (+4.57\%) on January 17, 1991, was caused by Gulf War I, with the launching of the operation Desert Storm, in particular with the announcement of the success of the US air raids against Iraq.

\footnotetext{
${ }^{14}$ Choudhry (2010) investigates the potential effects of the WWII events on the movements of the DJIA stock price index and returns volatility. Events during a war affect the equity markets in two ways: (i) it can increase or decrease the price of shares and the returns volatility, (ii) it can alter the uncertainty of the investors about the future profitability of the equities and their risk.
} 


\subsubsection{Monetary Policy during Recessions ${ }^{15}$}

1969-1970 Recession. The increase in the DJIA (+3.85\%) on August 16, 1971 is due to the anti-inflationary program of the President Richard Nixon, which specifies a series of drastic economic measures (tight monetary policy) including a wage-price freeze, intended to lift the US out of its 1969-1970 recession.

1981-1982 Recession. The rise of the DJIA (+4.05\%) on August 17, 1982, can be explained by the interest rate decline and the debt crisis due to the announcement by Latin American countries, especially Mexico, that they could not repay their foreign debt. An expectation of further declines in interest rates to help the economy recover can explain the rise of the DJIA (+4.09\%) on October 6, 1982.

1991-2001 Expansion. The fall of DJIA (-2.43\%) on April 02, 1994, can be explained by the Fed's surprise announcement that it rises US interest rates for the first time in five years. The announcement of the surprisingly sharp rise in job numbers, suggesting no further US interest rate cuts can explained the fall of DJIA (-3.05\%) on March 09, 1996.

\subsubsection{Macroeconomic News and Declarations on the Economic Situation}

1938-1945 Expansion. On April 9, 1943, President Franklin Roosevelt's anti-inflation order governing prices and wages can explain the drop in the DJIA (-3.17\%).

1946-1948 Expansion. The declines in the DJIA (-5.56\%) on September 3, 1946, can be explained by labor unrest in the maritime and trucking industries. The fall of the DJIA (-3.89\%) on April 14, 1947, can be explained by the worsening of the economic situation and the fear of new strikes.

1961-1969 Expansion. The large movements in May and June 1962 can be explained by the economic situation. President John F. Kennedy forced the rollback of a steel price hike, which may explain the fall of the DJIA (-5.71\%) on May 28, 1962, because investors saw this decision as a rethinking of the principle of free enterprise.

\footnotetext{
${ }^{15}$ See Mishkin and White (2002) for a discussion of the implications for monetary policy of the stock market crashes.
} 
1982-1990 Expansion. The fall of DJIA (-3.26\%) on July 07, 1986, can be explained by a fear on the health of the US economy due to negative factors, primarily weak corporate profits and declines in production, new orders and employment in the industrial sector during June. The DJIA fell by $2.33 \%$ on April 14, 1988, following the announcement of the increase in the US trade deficit in February ( $\$ 13.8$ billion).

\subsubsection{The September 11 Terrorist Attacks}

The terrorist attacks in the US on September 11, 2001 affected stock markets around the world. The US markets remained closed for four days, whereas the European markets decided to remain open but felt the consequences of the terrorist attacks. The DJIA fell by "only" 7.13\% when the US markets reopened on September 17, 2001. Indeed, the US stock markets were supported by the interventions of the central banks, in particular the Fed ${ }^{16}$ and the European Central Bank, which lowered their interest rates, and by technical provisions on the repurchases of shares by companies. Such provisions are generally used to prevent a stock market crash. Moreover, the authorities intervened to dissuade the banks and trust companies from lending their securities to speculative funds, to discourage short selling transactions, which amplify market plunges.

\subsubsection{Bankruptcy}

The major banks' rejection of the plan to buy out United Airlines can explain the considerable losses in the DJIA $(-6.91 \%)$ on October 13, 1989. The crash was apparently caused by a reaction to a news story about the break-down of a $\$ 6.75$ billion leveraged buy-out deal for United Continental Holdings (UAL) Corporation, the parent

\footnotetext{
${ }^{16}$ The Fed took steps to provide a high level of liquidity ( $\$ 100$ billion) through the US banking and financial sector. The Fed policy thus calmed and stabilized the economy (Chen and Siems, 2004). On September 14, the Fed encouraged the banks to grant appropriations to the solvent borrowers and to modify the initial terms of the credit terms and other transactions, in particular lengthening the duration of repayment and reorganization of debt. See Chesney et al. (2011) for a discussion of the impact of terrorism on financial markets.
} 
company of United Airlines. Wall Street ( $+3.40 \%$ for DJIA) rebounds the October 16, 1989, with a very high trading volume (416.29 million shares).

\subsubsection{Regulation}

After an eleven-day interruption due to National Banking holiday, ${ }^{17}$ the NYSE reopened on March 15, 1933, with a strong rise $(+15.34 \%$ for the DJIA). It seems that the measures adopted by President Franklin Roosevelt to solve the banking crisis and to balance the budget reassured investors, especially the Emergency Banking Act or the Glass-Steagall $\mathrm{Act}^{18}$ (law to banks from engaging in speculation). These measures placed the market under governmental control, created restrictions on advances that brokers could receive and obliged brokers and the members of Stock Exchange to file daily reports on bank loans. ${ }^{19}$

\subsubsection{Miscellaneous}

The fall of the DJIA $(-3.29 \%)$ on February 27, 2007, can be explained by the collapse of Shanghai Stock Exchange due to the tightening of monetary policy of the Chinese government. Further, Alan Greenspan, former Fed's Chairman, declares that a recession could affect the US economy. Finally, investors are concerned about the shortcomings of high-risk loans ("subprime mortgage") granted to households less creditworthy. The two largest mortgage agencies Freddie Mac and Fannie Mae

\footnotetext{
${ }^{17}$ On March 6, 1933, the President Franklin Roosevelt imposes the closing of all the American banks for four days (banking holiday) which necessarily implies the closing the stock markets. For a discussion of the National banking holiday see Wigmore (1987), Schwert (1989b) and Butkiewicz (1999), inter alia.

${ }^{18}$ The Glass-Steagall Act, also called Banking Act of 1933, instituted incompatibility between trading by deposit and investment banks; created the federal system of bank deposit insurance (the Federal Deposit Insurance Corporation, FDIC); introduced the leveling off of the interest rates on bank deposits (Regulation Q). The Regulation was repealed in 1980 by the Depository Institutions Deregulation and Monetary Control Act, and the Glass-Steagall Act was abrogated on November 12, 1999, by the Financial Services Modernization Act (or Gramm-Leach-Bliley Act). See Moshirian (2011) for a discussion of regulations and market development.

${ }^{19}$ Thereafter, the Securities and Exchange Commission (SEC) - the federal organization of regulation and control of the financial markets - was created on June 6, 1934.
} 
announced that they would tighten the criteria for this type of refinancing loans. The US equity markets (-5.55\% for DJIA) have fallen quickly in reaction to the Standard \& Poor's decision to downgrade the US credit rating from AAA to AA+.

\section{Volatility changes in the DJIA}

We find that some negative and positive high returns experienced by the DJIA are not identified as outliers, namely as extraordinary (rare) movements, due to the very high volatility of some periods (see, e.g., Officer, 1973; Schwert, 1989a). This can be explained by differing consequences and perceptions of the investors when the market is experiencing high volatility rather than low volatility or stability. Therefore, we use an appropriate methodology to identify breakpoints and sudden shifts in volatility of the DJIA. A relatively recent approach to test for volatility shifts is the iterative cumulative sums of squares (ICSS) algorithm proposed by Inclán and Tiao (1994) and improves by Sansó et al. (2004). This algorithm allows the detection of multiple breakpoints in variance and has been used extensively to identify changes in volatility of financial time series (Fernandez, 2006; Hammoumdeh and Li, 2008; Kasman, 2009, among others). ${ }^{20}$ Nevertheless, Rodrigues and Rubia (2011) show that the asymptotic distribution of the ICSS test statistics varies under additive outliers. The critical values from this distribution generally prove inadequate for the test, which finds too many breaks. ${ }^{21}$ Therefore, using the outlier-adjusted DJIA return series, we apply the modified ICSS algorithm to detect sudden changes in volatility.

\subsection{Sudden change detection}

The most popular statistical methods specifically designed to detect breaks in volatility are CUSUM-type tests. As underlined by Rodrigues and Rubia (2011), the ability

\footnotetext{
${ }^{20}$ Haugen et al. (1991) used the methodology developed by Wichern et al. (1976) for identifying variance change points in the DJIA over the period 1897-1988.

${ }^{21}$ Further, Inclán and Tiao (1994) advised that "it is advisable to complement the search for variance changes with a procedure for outlier detection".
} 
of the CUSUM tests to identify structural changes depends of the underlying assumptions. Financial data display a time varying volatility pattern, known as volatility clustering. Andreou and Ghysels (2002) illustrate the pervasive effect of persistent volatility on CUSUM-type tests experimentally. Their results indicate that the Kokoszka and Leipus (2000) test is robust to conditional heteroscedasticity. Sansó et al. (2004) propose a more general test than that of Kokoszka and Leipus (2000) based on the iterative cumulative sum of squares (ICSS) algorithm developed by Inclán and Tiao (1994).

Let $r_{i, t}=100 \times \log \left(P_{i, t} / P_{i, t-1}\right)$, where $P_{i, t}$ is the price of the index $i$ at the time $t$, so that $r_{t}$ is the percent return of the index $i$ from period $t-1$ to $t .\left\{r_{t}\right\}$ is then assumed to be a series of independent observations from a normal distribution with zero mean and unconditional variance $\sigma_{t}^{2}$ for $t=1, \ldots, T$. Assume that the variance within each interval is denoted by $\sigma_{j}^{2}, j=0,1, \ldots, N_{T}$, where $N_{T}$ is the total number of variance changes, and $1<\kappa_{1}<\kappa_{2}<\cdots<\kappa_{N_{T}}<T$ are the set of breakpoints. Then the variances over the $N_{T}$ intervals are defined as

$$
\sigma_{t}^{2}= \begin{cases}\sigma_{0}^{2}, & 1<t<\kappa_{1} \\ \sigma_{1}^{2}, & \kappa_{1}<t<\kappa_{2} \\ \cdots & \\ \sigma_{N_{T}}^{2}, & \kappa_{N_{T}}<t<T\end{cases}
$$

The cumulative sum of squares is used to estimate the number of variance changes and to detect the point in time of each variance shift. The cumulative sum of the squared observations from the beginning of the series to the $k$ th point in time is expressed as $C_{k}=\sum_{t=1}^{k} r_{t}^{2}$ for $k=1, \ldots, T$. To test the null hypothesis of constant unconditional variance, the Inclán-Tiao statistic is given by:

$$
I T=\sup _{k}\left|\sqrt{T / 2} D_{k}\right|
$$

where $D_{k}=\left(\frac{C_{k}}{C_{T}}\right)-\left(\frac{k}{T}\right)$, with $C_{T}$ is the sum of the squared residuals from the whole sample period. The value of $k$ that maximizes $\left|\sqrt{T / 2} D_{k}\right|$ is the estimate of the break date. The ICSS algorithm systematically looks for breakpoints along the sample. If 
there are no variance shifts over the whole sample period, $D_{k}$ will oscillate around zero. Otherwise, if there are one or more variance shifts, $D_{k}$ will deviate from zero. The asymptotic distribution of the $I T$ statistic is given by $\sup _{r}\left|W^{*}(r)\right|$, where $W^{*}(r)=W(r)-r W(1)$ is a Brownian bridge and $W(r)$ is standard Brownian motion. Finite-sample critical values can be generated by simulation.

The IT statistic is designed for i.i.d. processes, which is a very strong assumption for financial data, in which there is evidence of conditional heteroscedasticity. Sansó et al. (2004) show that the size distortions are important for heteroscedastic conditional variance processes from Monte Carlo simulations. Their results thus invalidate the practical use of this test for financial time series. To overcome this problem, Sansó et al. (2004) propose a new test that explicitly consider the fourth moment properties of the disturbances and the conditional heteroscedasticity. ${ }^{22}$ They propose a nonparametric adjustment to the $I T$ statistic that allows $r_{t}$ to obey a wide class of dependent processes under the null hypothesis. Consistent with Sansó et al. (2004), we use a non-parametric adjustment based on the Bartlett kernel, and the adjusted statistic $^{23}$ is given by:

$$
A I T=\sup _{k}\left|T^{-0.5} G_{k}\right|
$$

where $G_{k}=\hat{\lambda}^{-0.5}\left[C_{k}-\left(\frac{k}{T}\right) C_{T}\right], \hat{\lambda}=\hat{\gamma}_{0}+2 \sum_{l=1}^{m}\left[1-l(m+1)^{-1}\right] \hat{\gamma}_{l}, \hat{\gamma}_{l}=T^{-1} \sum_{t=l+1}^{T}\left(r_{t}^{2}-\right.$ $\left.\hat{\sigma}^{2}\right)\left(r_{t-l}^{2}-\hat{\sigma}^{2}\right), \hat{\sigma}^{2}=T^{-1} C_{T}$, and the lag truncation parameter $m$ is selected using the procedure in Newey and West (1994). Under general conditions, the asymptotic distribution of AIT statistic is also given by $\sup _{r}\left|W^{*}(r)\right|$, and finite-sample critical values can be generated by simulation.

\footnotetext{
${ }^{22}$ Bacmann and Dubois (2002) show that one way to circumvent this problem is by filtering the return series by a GARCH $(1,1)$ model, and applying the ICSS algorithm developed by Inclán and Tiao (1994) to the standardized residuals obtained from the estimation. Fernandez (2006) proposes an alternative approach to testing for variance homogeneity based on wavelet analysis.

${ }^{23}$ This adjusted statistic is equivalent to the non-parametric test proposed by Kokoszka and Leipus (2000).
} 


\subsection{Sudden changes in the DJIA}

As suggested by Rodrigues and Rubia (2011), the modified ICSS algorithm proposed by Sansó et al. (2004) is applied on outlier-adjusted returns of DJIA. Table 5 displays the time periods of a shift in DJIA volatility, and descriptive statistics for the return series on sub-periods identified from volatility shifts. The modified ICSS algorithm finds changes in volatility, with periods of low, medium and high volatility, especially episodes of high volatility occurring during the 1929-1934 recession, the 1937-1938 contraction, and the period of the 2007-08 financial crisis ${ }^{24}$ and the related recession (2007-2011). Figure (2 displays the conditional variance for each sub-periods. This result confirms the findings of Schwert (1989a,b) and Hamilton and Lin (1996) that volatility of stock returns increases during (severe) recessions. Episodes of higher volatility occur in the 1929-1934 and 1937-1938, with a standard deviation of 0.020 , present at least twice the volatility as the other periods, as found by Schwert (1989b) (see also Officer, 1973; Schwert, 1989a, 1998). ${ }^{25}$ Voth (2003) advocates that this high volatility can be explained by the political uncertainty. Further, we show that the 2007-2011 period is associated with very high levels of volatility (standard deviation of 0.016) then the DJIA returns to a period of "normal" (or less high). The 2007-2011 period seems to be characterized by prolonged periods (many years) of high volatility, as for the 1929-1934 recession period, but with a slightly less level of volatility. ${ }^{26} \mathrm{We}$ also observe a long "tranquil" period from 1942 to 1972. All the returns in the subperiods exhibit excess skewness, excess kurtosis and conditional heteroscedasticity.

\footnotetext{
${ }^{24}$ See, e.g., Bartram and Bodnar (2009) and Mishkin (2010) for a discussion of the 2008-2009 financial crisis.

${ }^{25}$ Schwert (1989b) finds that the sub-periods 1929-1934 and 1937-1938 exhibit high volatility from a switching-regime Markov model (with two regimes) for a monthly constructed stock-return series based largely on data from the Center for Research in Security Prices (CRSP) for the 1834-1987 period.

${ }^{26}$ Schwert (2011) uses monthly returns of a daily index of New York Stock Exchange-listed stocks from 1885-2010, principally based on data from the CRSP and the S\&P 500. He finds contrast between the period following the 2008 financial crisis and the Great Depression in terms of standard deviation. Andrada et al. (2012) also finds that the 1929-1934 period exhibits sharper tail events than the 2007-2011 period by analyzing the historical distributions of the DJIA.
} 


\section{Discussion on risk management}

Risk management is one of the most important innovations of the latter century. Valueat-risk ( $\mathrm{VaR}$ ) is the most prominent of a set of risk measurement tools to be developed in response to a series of huge, widely publicized losses at large financial firms in the 80 's.

From a statistical point of view, VaR is a quantile of the profit-loss distribution, which can be derived for any specific level of significance $(\alpha)$ and time horizon. ${ }^{27}$ Financial managers estimate the quantile of the left lower-sided tail, as a representation of worst losses for a given $(\alpha)$. Providing an accurate estimate of VaR is crucial. If the underlying risk is not properly estimated, this may lead to a suboptimal capital allocation with consequences on the profitability or the financial stability of the institutions and if risk is overestimated, then it may further lead to unnecessary extra capital requirements.

The parametric methods for estimating VaR assume one particular distribution for the data series. The Gaussian approach implies that the returns follow a Gaussian distribution. As it is well known that the standard deviation of the returns change over time, we have to use models that explicitly allow the standard deviation to change of time that provide better forecasts of variance and by extension better measures of VaR (Engle, 2011).

Nevertheless, the presence of outliers may have undesirable effects on the estimates of the parameters of the equation governing volatility dynamics (see, e.g., Friedman and Laibson, 1989; Van Dijk et al., 1999; Mendes, 2000; Ng and McAleer, 2004; Charles, 2008), the tests of conditional homoscedasticity (see, e.g., van Dijk et al., 1999; Carnero et al., 2001, 2007), and the out-of-sample volatility forecasts (see, e.g., Franses and Ghijsels, 1999; Carnero et al., 2007; Catalán and Trívez, 2007; Charles, 2008)..$^{28}$

\footnotetext{
${ }^{27} \mathrm{VaR}$ quantifies the potential loss for a portfolio of assets $\left(r_{t}\right)$ under normal market condition over a given period of time horizon $h$ with a certain confidence level $(1-\alpha)$, at time $t$ conditionnally on available information $\Omega_{t-1}: P\left\{\left(r_{t} \geq \operatorname{VaR}_{t, h}(\alpha) \mid \Omega_{t-1}\right\}\right.$.

${ }^{28}$ Estrada (2009) show that a few outliers have a massive impact on long term performance from the
} 
As one of the important steps in the estimation of VaR involves obtaining an estimate of the volatility, we illustrate the effect of the outliers in estimating VaR. Our insample period runs from October 2, 1928 to December 31, 2011, while the out-ofsample period runs from January 02, 2013. We estimate one-day-ahead VaR from (1) original returns, and (2) free-outlier returns, based on GJR-GARCH model ${ }^{29}$ and daily squared returns as proxy of daily volatility ${ }^{30}$ For comparison we use mean VaR $(\overline{V a R})$, the failure ratio which is the percentage of negative returns smaller than onstep-ahead VaR, the LR Kupiec and DQ stat are the Kupiec (1995) likelihood ratio test and the dynamic quantile (DQ) test of Engle and Manganelli (2004), respectively, for the VaR evaluations (also known as backtests) under 95\% and 99\% confidence levels. However, the VaR is not considered as a coherent measure of risk in the sense of Artzner et al. (1999). ${ }^{31}$ Expected shortfall is a coherent measure of risk and it is defined as the expected value of the losses conditional on the loss being larger than the VaR. ${ }^{32}$ Hendricks (1996) indicates that two measures can be constructed: (i) the expected value of loss exceeding the VaR level (ESF1), and (ii) the expected value of loss exceeding the VaR level, divided by the associated VaR values (ESF2). The results in Table 2 show that the risk measures based on outlier-free data are better than those from original data. These results suggest that taking into account the outliers is important for risk managers with respect to risk measure assessment, such as VaR and expected shortfall.

We also compare the different sub-periods with some in-sample risk measures (VaR and ES) under 95\% confidence level. Table 6 displays the results and confirms

\footnotetext{
DJIA over the 1900-2006 period.

${ }^{29} \mathrm{We}$ do not search the best volatility models for computing VaR, but this point will be examined in future research

${ }^{30}$ Our results are not sensitive to the choice of volatility proxy.

${ }^{31}$ In the properties a coherent measure functional must satisfy on an appropriate probabilistic space, the sub-additivity property does not hold for all cases. Specific portfolios can be constructed where the risk of a portfolio with two assets can be greater than the sum of the individual risks therefore, violating sub-additivity and in general the diversification principle (Scaillet, 2000).

${ }^{32}$ The expected shortfall is defined as: $E S F_{t}=E\left(\left|L_{t}\right|>\left|V a R_{t}\right|\right)$, where $L_{t}$ is the expected value of loss if a $\operatorname{VaR}_{t}$ violation occurs.
} 
that the three periods of high volatility, i.e. 1929-1934, 1937-1938 and 2008-2011, are riskier because they exhibit higher risk measures, especially the mean $\operatorname{VaR}(\overline{V a R})$ and the expected shortfall (ESF1). Further, the periods with low volatility, i.e. 1942-1972, 2003-2207 and 2001-2013, are less risky with levels of the $\overline{V a R}$ and ESF1 sometimes two times lower than the periods of high volatility. ${ }^{33}$ These results show the relevance of differencing the volatility regimes for risk management.

Another way to estimate the VaR is the extreme value theory (EVT). Indeed the Gaussian method can fail when the return distribution is fat-tailed. The EVT provides statistical tools to estimate the tails of probability distribution. As underlined by Gonzalo and Olmo (2004), the first task is to identify which values are really extreme. The authors propose a formal way of identifying and estimating the extreme values of any random sample of size $n$ coming from a distribution function $(F)$ that is to distinguish between extreme returns and outlying returns. They provide accurate approximations of the extreme quantiles of $F$ and show that identification of the real extreme observations allows to estimate a VaR very accurately.

\section{Conclusion}

This study examined the kinds of events that cause large shocks, considered as black swans or rare events, in the volatility of the DJIA index between October 2, 1928 and August 30, 2013. More precisely, from the semi-parametric procedure to detect additive outliers proposed by Laurent, Lecourt and Palm (LLP) (2013) based on the GJR model, we determined when these (positive and negative) large changes in volatility of daily returns occur during this period. We also tried to associate the date of each outlier with a specific (economic, political or financial) event that occurred near that date, and many of them seem to be associated with the same event

\footnotetext{
${ }^{33}$ Note that the VaR models for some sub-periods are rejected by the LR Kupiec and DQ tests. The VaR model is not rejected for the 1937-1938 sub-period but this result should be take with caution due to the bad small sample properties of backtesting tests.
} 
patterns. We found that the large volatility shocks are principally due to the major financial crashes, the US elections, wars, monetary policies during the recessions, macroeconomic news and declarations on the economic situation, terrorist attacks, bankruptcy, and regulation. This finding suggests that these large shocks should be thus taken into account in modelling volatility of returns along with in macro-finance models.

We also showed that some shocks were not identified as extraordinary movements due to their occurring during high volatility episodes, especially the 1929-1934, 1937-1938 and 2007-2011 periods, identified from the ICSS algorithm. This can be explained by differing consequences and perceptions of the investors on larger changes in percentage when the market is within a high volatility period compared with a low volatility period or a stable period, especially in a context of uncertainty about the future profitability of equities and their risk. Further, in contrast to Schwert (2011), we showed that the period of the 2007-08 financial crisis and the related recession (2007-2011) exhibit the same characteristic than the 1929-1934 recession period: very high levels of volatility on prolonged periods (many years). This study focuses on the events that cause large shocks in the volatility of US stock market. It will be interesting to study others stock markets and/or financial markets, such as bond and foreign exchange rate markets, to compare the market's reactions to such events. 


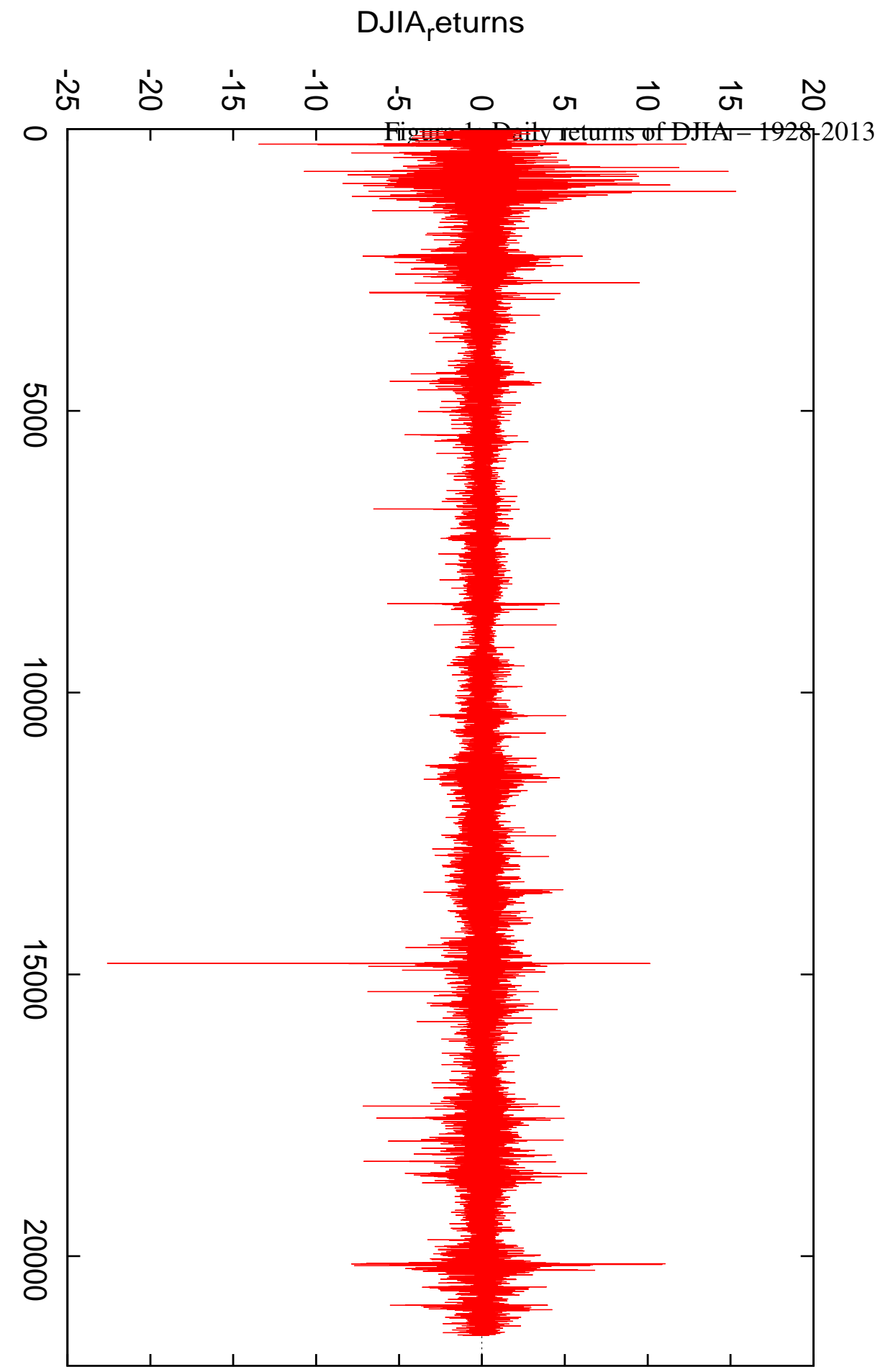


Table 1: Summary statistics of the DJIA: 1928-2013.

\begin{tabular}{lccccccc}
\hline \hline Series & Mean (\%) & St. dev. & Min. & Max. & Skewness & Excess Kurtosis & LM(10) \\
\hline Non-adjusted & 0.0259 & 0.012 & -0.226 & 0.153 & $-0.169^{*}$ & $20.87^{*}$ & $2738.9^{*}$ \\
Outlier-adjusted & 0.0302 & 0.011 & -0.107 & 0.114 & -0.026 & $9.01^{*}$ & $4329.9^{*}$ \\
\hline \hline
\end{tabular}

Notes: ${ }^{*}$ and ${ }^{* *}$ mean significant at $5 \%$ and $10 \%$ level, respectively.

Table 2: Out-of-sample results for risk measures.

\begin{tabular}{lccccccccc}
\hline \hline Series & Quantile & $\overline{V a R}$ & $\begin{array}{c}\text { Failure } \\
\text { ratio }\end{array}$ & $\begin{array}{c}\text { LR } \\
\text { Kupiec }\end{array}$ & $\begin{array}{c}\text { p-value } \\
\text { Kupiec }\end{array}$ & $\begin{array}{c}\text { DQ } \\
\text { stat }\end{array}$ & DQ-value & ESF1 & ESF2 \\
\hline Non-adjusted & $5 \%$ & -1.212 & 0.044 & 0.382 & 0.537 & 0.366 & 0.545 & -1.590 & 1.440 \\
& $1 \%$ & -1.716 & 0.025 & 7.213 & 0.007 & 10.27 & 0.001 & -1.787 & 1.172 \\
Outlier-adjusted & $5 \%$ & -1.195 & 0.048 & 0.028 & 0.868 & 0.027 & 0.869 & -1.532 & 1.447 \\
& $1 \%$ & -1.692 & 0.025 & 7.213 & 0.007 & 10.27 & 0.001 & -1.787 & 1.217 \\
\hline \hline
\end{tabular}

Notes: The risk measures are computed under $95 \%$ and $99 \%$ confidence levels, i.e. $5 \%$ and $1 \%$ quantiles, on the $2012-$ 2013 period. $\overline{V a R}$ denotes the mean on-step-ahead VaR, the failure ratio is the percentage of negative returns smaller than on-step-ahead VaR, LR Kupiec and DQ stat are the Kupiec (1995) likelihood ratio test and the dynamic quantile (DQ) test of Engle and Manganelli (2004), respectively, for the VaR evaluations. ESF1 and ESF2 are expected shortfall measures defined as the expected value of loss exceeding the VaR level and the expected value of loss exceeding the VaR level, divided by the associated VaR values, respectively. 
Table 3: Large shocks detected in the DJIA: 1928-1948.

\begin{tabular}{|c|c|c|c|c|}
\hline Date & t-stat & $\begin{array}{l}\text { Point } \\
\text { Change }\end{array}$ & $\begin{array}{l}\text { Percent } \\
\text { Change }\end{array}$ & Events \\
\hline 10/28/1929 & 5.48 & -40.58 & -13.47 & Black Monday \\
\hline 10/29/1929 & 4.95 & -30.57 & -11.73 & Black Tuesday \\
\hline $10 / 30 / 1929$ & 4.87 & 28.40 & 12.34 & Massive purchases of stocks \\
\hline 06/16/1930 & 4.46 & -19.64 & -7.87 & $\begin{array}{l}\text { Hoover's announcement that he would sign } \\
\text { the Hawley-Smoot Tariff Act }\end{array}$ \\
\hline 06/22/1931 & 5.52 & 15.51 & 11.90 & Hoover debt moratorium proposal \\
\hline 10/06/1931 & 4.79 & 12.86 & 14.87 & Noise of constitution of banking syndicate \\
\hline 03/15/1933 & 5.65 & 8.26 & 15.34 & End of National banking holiday and Glass-Steagall Act \\
\hline 07/26/1934 & 4.34 & -6.06 & -6.62 & Fear of European conflict \\
\hline 01/23/1939 & 5.99 & -7.79 & -5.22 & Spanish Civil War \\
\hline 09/05/1939 & 6.68 & 12.87 & 9.52 & European conflict \\
\hline 05/10/1940 & 4.27 & -3.40 & -2.30 & World War II \\
\hline 05/13/1940 & 7.26 & -7.14 & -4.93 & World War II \\
\hline 05/14/1940 & 8.16 & -9.36 & -6.80 & World War II \\
\hline 05/17/1940 & 5.12 & -6.23 & -4.78 & World War II \\
\hline $05 / 21 / 1940$ & 5.54 & -8.30 & -6.78 & World War II \\
\hline 11/07/1940 & 5.41 & 5.77 & 4.37 & Roosevelt's reelection \\
\hline 04/09/1943 & 5.71 & -4.30 & -3.17 & Roosevelt's anti-inflation order \\
\hline 09/03/1946 & 5.92 & -10.51 & -5.56 & Labor unrest in maritime and trucking industries \\
\hline 04/14/1947 & 5.27 & -6.74 & -3.89 & Worsening of economic situation \\
\hline $11 / 03 / 1948$ & 6.43 & -7.30 & -3.85 & Truman defeats Dewey \\
\hline 11/05/1948 & 4.61 & -6.16 & -3.34 & Fear of reestablishment of earning taxes \\
\hline
\end{tabular}

Notes: The $t$-statistics are compared to the $5 \%$ critical value equal to 4.16 computed by Laurent et al. (2013). 
Table 4: Large shocks detected in the DJIA: 1949-2013.

\begin{tabular}{|c|c|c|c|c|}
\hline Date & t-stat & $\begin{array}{c}\text { Point } \\
\text { Change }\end{array}$ & $\begin{array}{l}\text { Percent } \\
\text { Change }\end{array}$ & Events \\
\hline $06 / 26 / 1950$ & 7.36 & -10.44 & -4.65 & Outbreak of Korean War \\
\hline 06/29/1950 & 4.87 & -7.96 & -3.71 & North Korea tanks entered Seoul; fear of long war \\
\hline 09/26/1955 & 15.07 & -31.89 & -6.54 & Eisenhower's heart attack \\
\hline 09/27/1955 & 4.29 & 10.37 & 2.28 & Good news of the Eisenhower's health \\
\hline $05 / 28 / 1962$ & 4.66 & -34.95 & -5.71 & Kennedy forces rollback of steel price hike \\
\hline $11 / 22 / 1963$ & -11.38 & -21.16 & -2.89 & President Kennedy's assassination \\
\hline $11 / 26 / 1963$ & 22.59 & 32.03 & 4.50 & Arrestation of the Kennedy's assassin \\
\hline 08/16/1971 & 3.85 & 32.93 & 3.85 & Nixon anti-inflationary program \\
\hline 08/17/1982 & 5.57 & 38.81 & 4.90 & Crisis of the debt; fall in interest rate \\
\hline $10 / 06 / 1982$ & 4.22 & 37.07 & 4.09 & Expectation of further decline of interest rates \\
\hline 07/07/1986 & 4.51 & -61.87 & -3.26 & Fear on the US economy \\
\hline 09/11/1986 & 5.54 & -86.61 & -4.61 & Fear of fall in interest rate and inflation \\
\hline $10 / 19 / 1987$ & 11.87 & -507.99 & -22.61 & Fear of a new decline of dollar \\
\hline $10 / 21 / 1987$ & 4.95 & 186.84 & 10.15 & Fall in interest rates \\
\hline 04/14/1988 & 4.90 & -101.46 & -2.33 & Increase of trade deficit \\
\hline 10/13/1989 & 12.30 & -190.58 & -6.91 & Rejection of repurchase plan of United Airlines \\
\hline $10 / 16 / 1989$ & 5.08 & 88.12 & 3.43 & Rebound \\
\hline 01/17/1991 & 4.79 & 114.60 & 4.57 & Operation Desert Storm \\
\hline $11 / 15 / 1991$ & 7.55 & -120.31 & -3.93 & Bad economic statistics; fear of economic stagnation \\
\hline 02/04/1994 & 5.60 & -96.24 & -2.43 & Unexpectedly rise of interest rates \\
\hline 03/08/1996 & 4.43 & -171.24 & -3.04 & Surprisingly sharp rise in job numbers \\
\hline $10 / 27 / 1997$ & 6.00 & -554.26 & -7.18 & Asian crisis \\
\hline 08/31/1998 & 4.66 & -512.61 & -6.37 & Deterioration of Asian and Russian crises \\
\hline 09/17/2001 & 5.97 & -684.81 & -7.13 & The September 11 terrorist attacks \\
\hline $02 / 27 / 2007$ & 7.58 & -416.02 & -3.29 & Fall of Shanghai Stock Exchange; fear of recession \\
\hline 08/08/2011 & 4.44 & -634.76 & -5.55 & S\&P downgrades the US credit rating \\
\hline
\end{tabular}

Notes: The $t$-statistics are compared to the $5 \%$ critical value equal to 4.16 computed by Laurent et al. (2013). 
Table 5: Sudden changes in DJIA volatility and summary statistics on sub-periods.

\begin{tabular}{lcccccccc}
\hline \hline $\begin{array}{l}\text { Dates of } \\
\text { change breaks }\end{array}$ & $\begin{array}{c}\text { volatility } \\
\text { regimes }\end{array}$ & $\begin{array}{c}\text { Mean } \\
(\%)\end{array}$ & St. dev. & Min. & Max. & Skewness & Excess & LM(10) \\
\hline $10 / 02 / 1928-10 / 16 / 1934$ & high & -0.030 & 0.025 & -0.135 & 0.153 & $-0.354^{*}$ & $4.30^{*}$ & $157.1^{*}$ \\
$10 / 17 / 1934-08 / 25 / 1937$ & medium & 0.095 & 0.010 & -0.037 & 0.029 & $-0.446^{*}$ & $1.13^{*}$ & 9.9 \\
$08 / 26 / 1937-10 / 05 / 1938$ & high & -0.052 & 0.021 & -0.072 & 0.061 & $-0.217^{*}$ & $0.53^{*}$ & $16.3^{* *}$ \\
$10 / 06 / 1938-07 / 08 / 1942$ & medium & -0.028 & 0.011 & -0.068 & 0.095 & $-0.031^{*}$ & $10.73^{*}$ & $48.9^{*}$ \\
$07 / 09 / 1942-12 / 27 / 1972$ & low & 0.032 & 0.007 & -0.065 & 0.051 & $-0.422^{*}$ & $5.77^{*}$ & $595.6^{*}$ \\
$12 / 29 / 1972-12 / 15 / 1995$ & medium & 0.030 & 0.010 & -0.226 & 0.101 & $-1.853^{*}$ & $49.53^{*}$ & $374.2^{*}$ \\
$12 / 18 / 1995-04 / 02 / 2003$ & medium+ & 0.033 & 0.012 & -0.072 & 0.064 & $-0.132^{*}$ & $3.05^{*}$ & $157.8^{*}$ \\
$04 / 03 / 2003-07 / 09 / 2007$ & low & 0.048 & 0.007 & -0.033 & 0.022 & $-0.088^{*}$ & $0.86^{*}$ & $31.3^{*}$ \\
$07 / 10 / 2007-12 / 20 / 2011$ & high & 0.002 & 0.016 & -0.079 & 0.111 & $0.197^{*}$ & $6.90^{*}$ & $189.3^{*}$ \\
$12 / 21 / 2011-08 / 30 / 2013$ & low & 0.048 & 0.007 & -0.024 & 0.024 & $-0.097^{*}$ & $1.20^{*}$ & $15.35^{*}$ \\
\hline \hline
\end{tabular}

Notes: ${ }^{*}$ and ${ }^{* *}$ mean significant at $5 \%$ and $10 \%$ level, respectively. 
Table 6: In-sample results for risk measures on sub-periods.

\begin{tabular}{lcccccccc}
\hline \hline Sub-periods & $\overline{V a R}$ & Failure & LR & p-value & DQ & p-value & ESF1 & ESF2 \\
& & ratio & Kupiec & Kupiec & stat & DQ & & \\
\hline $10 / 02 / 1928-10 / 16 / 1934$ & -4.853 & 0.061 & 3.700 & 0.054 & 31.53 & 0.000 & -4.445 & 1.372 \\
$10 / 17 / 1934-08 / 25 / 1937$ & -2.134 & 0.059 & 1.073 & 0.300 & 10.22 & 0.116 & -1.971 & 1.474 \\
$08 / 26 / 1937-10 / 05 / 1938$ & -4.647 & 0.061 & 0.635 & 0.425 & 3.174 & 0.787 & -4.459 & 1.441 \\
$10 / 06 / 1938-07 / 08 / 1942$ & -2.570 & 0.079 & 4.130 & 0.042 & 16.86 & 0.001 & -2.349 & 1.319 \\
$07 / 09 / 1942-12 / 27 / 1972$ & -1.195 & 0.064 & 1.108 & 0.293 & 18.29 & 0.006 & -1.223 & 1.520 \\
$12 / 29 / 1972-12 / 15 / 1995$ & -2.126 & 0.054 & 0.074 & 0.786 & 27.88 & 0.000 & -2.157 & 1.211 \\
$12 / 18 / 1995-04 / 02 / 2003$ & -1.563 & 0.064 & 1.108 & 0.293 & 5.134 & 0.527 & -1.477 & 1.470 \\
$04 / 03 / 2003-07 / 09 / 2007$ & -1.512 & 0.064 & 1.108 & 0.293 & 6.202 & 0.401 & -1.436 & 1.247 \\
$07 / 10 / 2007-12 / 20 / 2011$ & -2.637 & 0.075 & 3.215 & 0.073 & 14.62 & 0.024 & -2.353 & 1.289 \\
$12 / 21 / 2011-08 / 30 / 2013$ & -1.424 & 0.061 & 0.635 & 0.425 & 3.174 & 0.787 & -1.450 & 1.446 \\
\hline \hline
\end{tabular}

Notes: The risk measures are computed under $95 \%$ confidence level. $\overline{V a R}$ denotes the mean on-step-ahead VaR, the failure ratio is the percentage of negative returns smaller than on-step-ahead VaR, LR Kupiec and DQ stat are the Kupiec (1995) likelihood ratio test and the dynamic quantile (DQ) test of Engle and Manganelli (2004), respectively, for the VaR evaluations. ESF1 and ESF2 are expected shortfall measures defined as the expected value of loss exceeding the VaR level and the expected value of loss exceeding the VaR level, divided by the associated VaR values, respectively. 
Figure 2: Conditional volatility of DJIA - 1928-2013

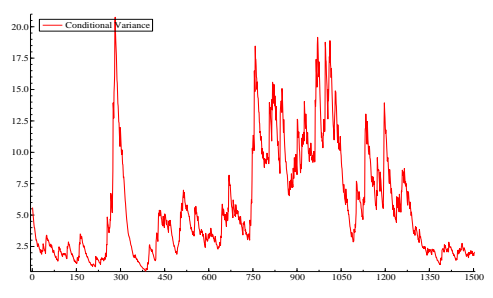

(a) $1928-1934$

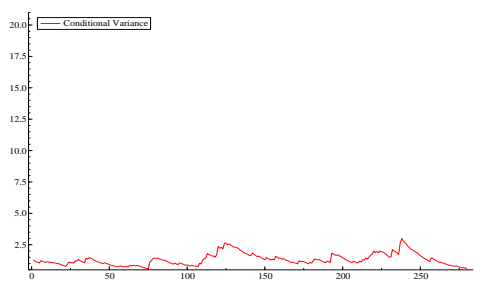

(d) $1938-1942$

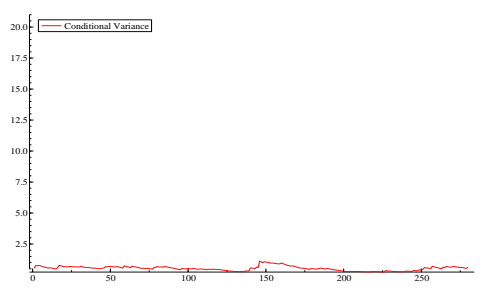

(g) 1995-2003

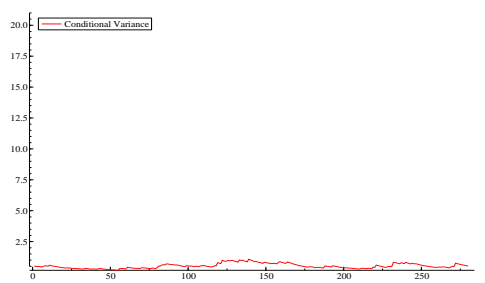

(j) 2011-2013

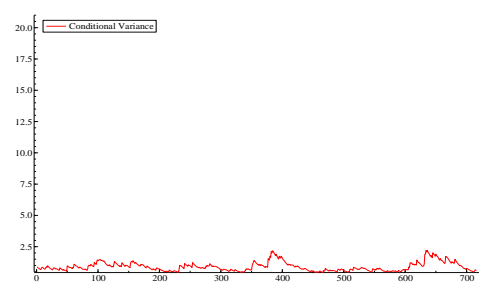

(b) 1934-1937

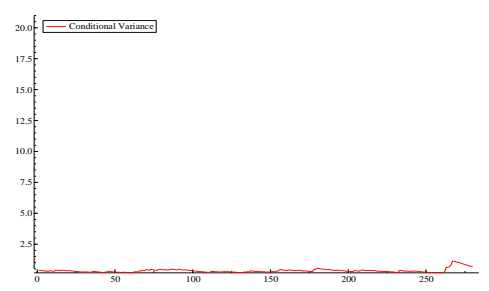

(e) $1942-1972$

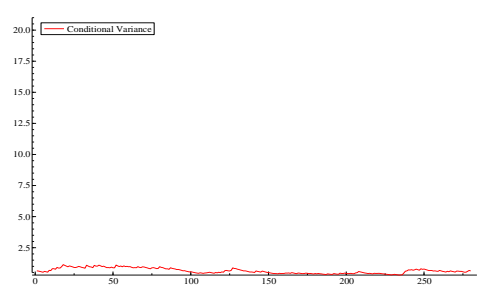

(h) 2003-2007

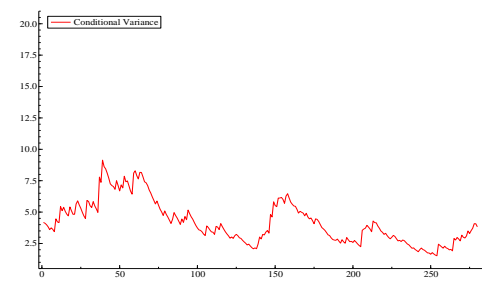

(c) $1937-1938$

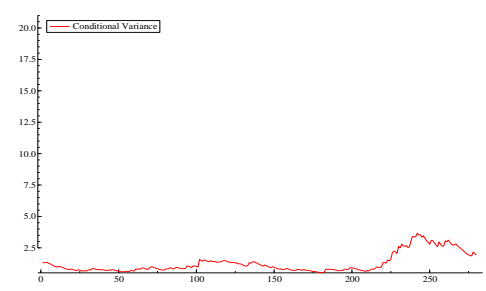

(f) 1972-1995

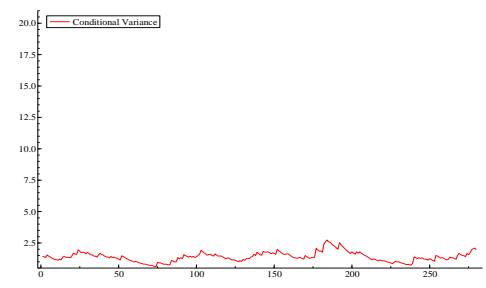

(i) $2007-2011$ 
Table 7: Largest daily percentage changes and losses on the DJIA, October 1928 December 2010.

\begin{tabular}{|c|c|c|c|c|}
\hline \multirow[b]{2}{*}{ Rank } & \multicolumn{2}{|c|}{ Largest changes } & \multicolumn{2}{|c|}{ Largest losses } \\
\hline & Date & $\%$ change & Date & $\%$ change \\
\hline 1 & 19/10/1987 & -22.61 & 19/10/1987 & -22.61 \\
\hline 2 & $15 / 03 / 1933$ & +15.34 & 28/10/1929 & -12.82 \\
\hline 3 & 06/10/1931 & +14.87 & 29/10/1929 & -11.73 \\
\hline 4 & 28/10/1929 & -12.82 & $10 / 05 / 1931$ & -10.74 \\
\hline 5 & $31 / 10 / 1929$ & +12.34 & 06/11/1929 & -9.92 \\
\hline 6 & $29 / 10 / 1929$ & -11.73 & $12 / 08 / 1932$ & -8.40 \\
\hline 7 & 21/09/1932 & +11.36 & $26 / 10 / 1987$ & -8.04 \\
\hline 8 & $13 / 10 / 2008$ & +11.08 & $15 / 10 / 2008$ & -7.87 \\
\hline 9 & $28 / 10 / 2008$ & +10.88 & 21/07/1933 & -7.84 \\
\hline 10 & $10 / 05 / 1931$ & -10.74 & $01 / 12 / 2008$ & -7.70 \\
\hline 10 & $21 / 10 / 1987$ & +10.15 & 09/10/2008 & -7.33 \\
\hline 11 & 06/11/1929 & -9.92 & $18 / 10 / 1937$ & -7.20 \\
\hline 12 & 03/08/1932 & +9.52 & 27/10/1997 & -7.18 \\
\hline 13 & $11 / 02 / 1932$ & +9.47 & 05/10/1932 & -7.15 \\
\hline 14 & $14 / 11 / 1929$ & +9.36 & $17 / 09 / 2001$ & -7.13 \\
\hline 15 & $18 / 12 / 1931$ & +9.35 & 24/09/1931 & -7.07 \\
\hline 16 & $13 / 02 / 1932$ & +9.19 & 20/07/1933 & -7.07 \\
\hline 17 & 06/05/1932 & +9.08 & $29 / 09 / 2008$ & -6.98 \\
\hline 18 & $19 / 04 / 1933$ & +9.03 & $13 / 10 / 1989$ & -6.91 \\
\hline 19 & 08/10/1931 & +8.70 & 08/01/1988 & -6.85 \\
\hline
\end{tabular}




\section{References}

[1] Akhigbe A., Martin A.D. and Whyte A.M. (2005). Contagion effects of the world's largest bankruptcy: The case of WorldCom. The Quaterly Review of Economics and Finance, 45, 48-64.

[2] Amihud Y. and Wohl A. (2004). Political news and stock prices: The case of the Saddam Hussein contracts. Journal of Banking and Finance, 28, 1185-1200.

[3] Andersen T.G., Bollerslev T. and Dobrev D. (2007): Noarbitrage semi-martingale restrictions for continous-time volatility models subject to leverage effects, jumps and i.i.d. noise: Theory and testable distributional implications. Journal of Econometrics, 138, 125-180.

[4] Andrada-Félixa J., Fernández-Rodrígueza F. and Sosvilla-Rivero S. (2012). Historical financial analogies of the current crisis. Economics Letters, 116, 190192.

[5] Artzner P., Delbaen F., Eber J-M. and Heath D. (1999). Coherent measures of risk. Mathematical Finance, 9, 203-228.

[6] Bacmann J.F. and Dubois M. (2002). Volatility in emerging stock markets revisited. European Financial Management Association, London Meeting, 26-29 June 2002.

[7] Balke N.S. and Fomby T.B. (1994). Large shocks, small shocks, and economic fluctuations: Outliers in macroeconomic time series. Journal of Applied Econometrics, 9, 181-200.

[8] Barro R.J. (2006). Rare disasters and asset markets in the Twentieth Century. Quarterly Journal of Economics, 121, 823-866.

[9] Barro R.J. and Ursúa J.F. (2009). Stock-market crashes and depressions. Working Paper No 1470, NBER. 
[10] Bartram S.M. and Bodnar G.M. (2009). No place to hide: The global crisis in equity markets in 2008/2009. Journal of International Money and Finance, 28, 1246-1292.

[11] Berkman H., Jacobsen B. and Lee J.B. (2011). Time-varying rare disaster risk and stock returns. Journal of Financial Economics, 101, 313-332.

[12] Bialkowski J., Gottschalk K. and Wisniewski T.P. (2008). Stock market volatility around national elections. Journal of Banking and Finance, 3, 1941-1953.

[13] Bierman H. (1998). The Causes of the 1929 Stock Market Crash. Greenwood Press, Westport.

[14] Birz G. and Lott J.R. (2011). The effect of macroeconomic news on stock returns: New evidence from newspaper coverage. Journal of Banking and Finance, 35, 2791-2800.

[15] Black F. (1976). Studies of stock price volatility change. Proceedings of the 1976 Meetings of the Business and Economics Statistics Section, American Statistical Association, 177-181.

[16] Bloom N. (2009). The impact of uncertainty shocks. Econometrica, 77, 623-685.

[17] Bollerslev T. (1986). Generalized autoregressive conditional heteroskedasticity. Journal of Econometrics, 31, 307-327.

[18] Bollerslev T., Chou R.Y. and Kroner K.F. (1992). ARCH modeling in finance: A review of the theory and empirical evidence. Journal of Econometrics, 52, 5-59.

[19] Bomfim A.N. (2003). Pre-announcement effects, news effects, and volatility: Monetary policy and the stock market. Journal of Banking and Finance, 27, 133151.

[20] Boudt K., Danielsson J. and Laurent S. (2013). Robust forecasting of dynamic conditional correlation GARCH Models. International Journal of Forecasting, $29,244-257$. 
[21] Box G.E.P. and Tiao G.C. (1975). Intervention analysis with applications to economic and environmental problems. Journal of the American Statistical Association, 70, 70-79.

[22] Butkiewicz J.L. (1999). The Reconstruction Finance Corporation, the gold standard, and the banking panic of 1933. Southern Economic Journal, 66, 271293.

[23] Carlson M. (2006). A brief history of the 1987 stock market crash. Finance and Economics Discussion Series No 2007-13, Federal Reserve Board.

[24] Carnero M.A., Peña D. and Ruiz E. (2001). Outliers and conditional autoregressive heteroskedasticity in time series. Revista Estadistica, 53, 143-213.

[25] Carnero M.A., Peña D. and Ruiz E. (2007). Effects of outliers on the identification and estimation of the GARCH models. Journal of Time Series Analysis, 28, 471-497.

[26] Carnero M.A., Peña D. and Ruiz E. (2012). Estimating GARCH volatility in the presence of outliers. Economics Letters, 114, 86-90.

[27] Catalán B. and Trívez F.J. (2007). Forecasting volatility in GARCH models with additive outliers. Quantitative Finance, 7, 591-596.

[28] Chang I., Tiao G.C. and Chen C. (1988). Estimation of time series parameters in the presence of outliers. Technometrics, 30, 193-204.

[29] Charles A. (2008). Forecasting volatility with outliers in GARCH models. Journal of Forecasting, 27, 551-565.

[30] Charles A. and Darné O. (2005). Outliers and GARCH models in financial data. Economics Letters, 86, 347-352.

[31] Charles A. and Darné O. (2006). Large shocks and the September 11th terrorist attacks on international stock markets. Economic Modelling, 23, 683-698. 
[32] Chen C. and Liu L.M. (1993). Joint estimation of model parameters and outlier effects in time series. Journal of the American Statistical Association, 88, 284297.

[33] Chen A. and Siems T. (2004). The effects of terrorism on global capital markets. European Journal of Political Economy, 20, 349-366.

[34] Chesney M., Reshetar G. and Karaman M. (2011). The impact of terrorism on financial markets: An empirical study. Journal of Banking and Finance, 35, 253267.

[35] Choudhry T. (2010). World War II events and the Dow Jones industrial index. Journal of Banking and Finance, 34, 1022-1031.

[36] Cutler D.M., Poterba J.M. and Summers L.H. (1989). What moves stock prices. Journal of Portfolio Management, 15, 4-12.

[37] Darné O. and Charles A. (2011). Large shocks in U.S. macroeconomic time series: 1860-1988. Cliometrica, 5, 79-100.

[38] Doornik J.A. and Ooms M. (2005). Outlier detection in GARCH models. Discussion Paper No 2005-092/4, Tinbergen Institute.

[39] Engle R.F. (1982). Autoregressive conditional heteroscedasticity with estimates of the variance of United Kingdom inflations. Econometrica, 50, 987-1007.

[40] Engle R.F. (2011). Garch 101: The use of ARCH and GARCH models in applied econometrics. Journal of Economic Perspectives, 15, 157-168.

[41] Engle R.F. and Manganelli S. (2004). CAViaR: Conditional Autoregressive Value-at-Risk by regression quantiles. Journal of Business and Economic Statistics, 22, 367-381.

[42] Estrada J. (2009). Black swans, market timing, and the Dow. Applied Economics Letters, 16, 1117-1121. 
[43] Fernandez V. (2006). The impact of major global events on volatility shifts: Evidence from the Asian crisis and 9/11. Economic Systems, 30, 79-97.

[44] Flannery M.J. and Protopapadakis A.A. (2002). Macroeconomic factors do influence aggregate stock returns. Review of Financial Studies, 15, 751-782.

[45] Foerster S.R. and Schmitz J.J. (1997). The transmission of US election cycles to international stock returns. Journal of International Business Studies, 28, 1-27.

[46] Franses P.H. and Ghijsels H. (1999). Additive outliers, GARCH and forecasting volatility. International Journal of Forecasting, 15, 1-9.

[47] Franses P.H. and van Dijk D. (2000). Nonlinear Time Series Models in Empirical Finance. Cambridge University Press, Cambridge.

[48] Frey B. and Kucher M. (2000). History as reflected in capital markets: The case of World War II. Journal of Economic History, 60, 468-496.

[49] Friedman B.M. and Laibson D.I. (1989). Economic implications of extraordinary movements in stock prices. Brookings Papers on Economic Activity, 2, 137-185.

[50] French K.R., Schwert G.W. and Stambaugh R.F. (1987). Expected stock returns and volatility. Journal of Financial Economics, 19, 3-29.

[51] Galbraith J.K. (1997). The Great Crash of 1929, Boston: Houghton Mifflin.

[52] Gonzalo J. and Olmo J. (2004). Which extreme values are really extreme? Journal of Financial Econometrics, 2, 349-369.

[53] Hamilton J. and Lin G. (1996). Stock market volatility and the business cycle. Journal of Applied Econometrics, 5, 573-593.

[54] Hammoudeh S. and Li H. (2008). Sudden changes in volatility in emerging markets: The case of Gulf Arab stocks markets. International Review of Financial Analysis, 17, 47-63. 
[55] Haugen R.A., Talmor E. and Torous W.N. (1991). The effect of volatility changes on the level of stock prices and subsequent expected returns. The Journal of Finance, 46, 985-1007.

[56] Hendricks D. (1996). Evaluation of Value-at-Risk models using historical data. Economic Policy Review, 2, 39-70.

[57] Hotta L.K. and Tsay R.S. (2012). Outliers in GARCH processes. In Bell W.R, Holan S.H. and McElroy T.S. (eds) Economic Time Series: Modeling and Seasonality, 337-358, Chapman and Hall.

[58] Inclán C. and Tiao G.C. (1994). Use of cumulative sums of squares for retrospective detection of changes of variance. Journal of the American Statistical Association, 89, 913-923.

[59] Jones S.T. and Banning K. (2009). US elections and monthly stock market returns. Journal of Economic and Finance, 33, 273-287.

[60] Kasman A. (2009). The impact of sudden changes on the persistence of volatility: Evidence from the BRIC countries. Applied Economics Letters, 16, 759-764.

[61] Kokoszka P. and Leipus R. (2000). Change-point estimation in ARCH models. Bernoulli, 6, 513-539.

[62] Kupiec P.H. (1995). Techniques for verifying the accuracy of risk measurement models. Journal of Derivatives, 3, 73-84.

[63] Laurent S, Lecourt C. and Palm F.C. (2013). Testing for jumps in GARCH models, a robust approach. Working paper.

[64] Lee S.S. and Mykland P.A. (2008). Jumps in financial markets: a new nonparametric test and jump dynamics. Review of Financial studies, 21, 25352563. 
[65] Mendes B.V.M. (2000). Assessing the bias of maximum likelihood estimates of contaminated GARCH models. Journal of Statistical Computation and Simulation, 67, 359-76.

[66] Mishkin F.S. (2010). Over the cliff: From the subprime to the global financial crisis. Working Paper No 16609, NBER.

[67] Mishkin F.S. and White E.N. (2002). US stock market crashes and their aftermath: Implications for monetary policy. Working Paper No 8992, NBER.

[68] Moshirian F. (2011). The global financial crisis and the evolution of markets, institutions and regulation. Journal of Banking and Finance, 35, 502-511.

[69] Muler N., Peña D. and Yohai V. (2009). Robust estimation for ARMA models. The Annals of Statistics, 37, 816-840.

[70] Muler N. and Yohai V. (2008). Robust estimates for GARCH models. Journal of Statistical Planning and Inference, 138, 2918-2940.

[71] Ng H.G. and McAleer M. (2004). Recursive modeling of symmetric volatility in the presence of extreme observations. International Journal of Forecasting, 20, 115-129.

[72] Nierderhoffer V., Gibbs S. and Bullock J. (1970). Presidential elections and the stock market. Financial Analysts Journal, 26, 111-113.

[73] Nierderhoffer V. (1971). The analysis of world events and stock prices. Journal of Business, 44, 193-219.

[74] Officer R.R. (1973). The variability of the market factor of New York Stock Exchange. Journal of Business, 46, 434-453.

[75] Olson E., Miller S. and Wohar M.E. (2012). "Black swans" before the "black swan": Evidence from international LIBOR-OIS spreads. Journal of International Money and Finance, 31, 1339-1357. 
[76] Rangel J.G. (2011). Macroeconomic news, announcements, and stock market jump intensity dynamics. Journal of Banking and Finance, 35, 1263-1276.

[77] Rappoport P. and White E.N. (1993). Was there a bubble in the 1929 stock market? Journal of Economic History, 53, 549-574.

[78] Reilly W.B. and Lukseitch W.A. (1980). The market prefers republicans: Myth or reality? Journal of Financial and Quantitative Analysis, 15, 541-59.

[79] Rigobon R. and Sack B. (2005). The effects of war risk on U.S. financial markets. Journal of Banking and Finance, 29, 1769-1789.

[80] Rodrigues P.M.M. and Rubia A. (2011). The effects of additive outliers and measurement errors when testing for structural breaks in variance. Oxford Bulletin of Economics and Statistics, 73, 449-468.

[81] Sakata S. and White H. (1998). High breakdown point conditional dispersion estimation with application to S\&P 500 daily returns volatility. Econometrica, $66,529-567$.

[82] Sansó, A., Aragó V. and Carrion-i-Silvestre J. (2004). Testing for changes in the unconditional variance of financial time series. Revista de Economía Financiera, 4, 32-53.

[83] Santa-Clara P. and Valkanov R. (2003). The presidential puzzle: Political cycles and the stock market. Journal of Finance, 58, 1841-72.

[84] Scaillet O. (2000). Nonparametric estimation and sensitivity analysis of expected shortfall. Mathematical Finance, 14, 115-129.

[85] Schwert G.W. (1981). The adjustment of stock prices to information about inflation. Journal of Finance, 36, 15-29.

[86] Schwert G.W. (1989a). Why does stock market volatility change over time? Journal of Finance, 44, 1115-1153. 
[87] Schwert G.W. (1989b). Business cycles, financial crises, and stock volatility. Canegie-Rochester Conference Series on Public Policy, 31, 83-126.

[88] Schwert G.W. (1990). Stock volatility and the crash of 87. Review of Financial Studies, 3, 77-102.

[89] Schwert G.W. (1998). Stock market volatility: Ten years after the crash. Working Paper No 6381, NBER.

[90] Schwert G.W. (2011). Stock volatility during the recent financial crisis. European Financial Management, 17, 789-805.

[91] Shachmurove Y. (2012). A historical overview of financial crises in the United States. Global Finance Journal, 22, 217-231.

[92] Taleb N. (2007). The Black Swan. The Impact of the Highly Improbable. Random House.

[93] Taylor J.B. and Williams J.C. (2009). A black swan in the money market. American Economic Journal: Macroeconomics, 1, 58-83.

[94] Tsay R.S. (1986). Time series model specification in the presence of outliers. Journal of the American Statistical Association, 81, 132-141.

[95] van Dijk D., Franses P.H. and Lucas A. (1999). Testing for ARCH in the presence of additive outliers. Journal of Applied Econometrics, 14, 539-562.

[96] Voth H-J. (2003). Stock price volatility and political uncertainty: Evidence from the interwar period. Working Paper No 02-09, MIT.

[97] Wang J., Meric G., Liu Z. and Meric I. (2009). Stock market crashes, firm characteristics, and stock returns. Journal of Banking and Finance, 33, 15631574.

[98] White E.W. (1990). The stock market boom and crash of 1929 revisited. Journal of Economic Perspectives, 4, 67-83. 
[99] Wichern D.W., Miller R.B. and Hsu D.A. (1976). Changes of variance in firstorder autoregressive time series models-With an application. Journal of the Royal Statistical Society, Series C, 25, 248-256.

[100] Wigmore B.A. (1987). Was the Bank Holiday of 1933 caused by a run on the dollar? Journal of Economic History, 47, 739-755.

[101] Wolfers J. and Zitzewitz E. (2009). Using markets to inform policy: The case of the Iraq War. Economica, 76, 225-250.

[102] Zhang X. and King M. (2005). Influence in generalized autoregressive conditional heteroscedasticity processes. Journal of Business and Economic Statistics, 23, 118-129. 